\title{
Prediction of Plunging Depth Induced by Top Lance Gas Blowing onto a Low-melting-point Metal Bath
}

\author{
Shingo SATO, ${ }^{1) *}$ Makoto ANDO, ${ }^{1)}$ Jun OKADA, ${ }^{1)}$ Yoshiaki UEDA ${ }^{21}$ and Manabu IGUCHI ${ }^{3)}$ \\ 1) Steel Research Laboratory, JFE Steel Corporation, 1-1 Minamiwatarida-cho, Kawasaki-ku, Kawasaki City, Kanagawa, 210- \\ 0855 Japan. \\ 2) Faculty of Science and Engineering, Setsunan University, 17-8 Ikedanaka-machi, Neyagawa City, Osaka, $572-8508$ Japan. \\ 3) Professor Emeritus, Hokkaido University, Kita 13, Nishi 8, Kita-ku, Sapporo City, Hokkaido, 060-8628 Japan.
}

(Received on December 11, 2019; accepted on January 6, 2020; originally published in Tetsu-to-

Hagané, Vol. 105, 2019, No. 1, pp. 10-19)

\begin{abstract}
Experimental and numerical investigations were carried out with a water bath and a low-melting-point metal bath to understand the cavity formation behavior induced by gas blowing from a top lance set in the near field of the bath surface. Cavity formation behavior was classified by the critical gas velocity for droplet formation. The depth of the cavity formed in the near field of the gas jet was reasonably predicted by numerical simulation. A new empirical equation for the cavity depth as a function of a modified Froude number was proposed.
\end{abstract}

KEY WORDS: cavity depth; cold model; low-melting-point metal; Wood's metal; numerical simulation; modified Froude number.

\section{Introduction}

In the converter steelmaking process, a high flow rate oxygen jet is blown on the bath surface from a top lance for decarburization. The oxygen jet impinging on the bath surface creates a cavity and causes spitting and splashing of the molten metal. The droplets generated by fluctuation of the bath surface reduce iron yield by increasing dust generation, and also cause operational trouble due to adhesion of molten metal to the top lance and converter refractory. It is therefore desirable to elucidate the mechanism of spitting and splashing. ${ }^{1-21)}$

In general, oscillation of the bath surface increases as the distance between the top lance and the bath surface decreases, and as a result, both spitting of droplets and adhesion of the metal to the top lance increase. As a guideline for determining the lance height in actual operation, the value of $h_{\mathrm{n}} / d_{\mathrm{ni}}$, which is obtained by dividing the distance $h_{\mathrm{n}}$ from the lance tip to the bath surface by the inside diameter $d_{\text {ni }}$ of the lance, is set in the range over 10. ${ }^{16)}$ However, this reduces the mixing power at the bath surface and causes large energy loss. If bath surface fluctuations and droplet scattering can be suppressed, the top blowing lance can be installed at a position closer to the bath surface.

In past studies, many model experiments were carried out on the formation of the cavity and fluctuation of the bath surface caused by gas blowing from the top blowing lance when $h_{\mathrm{n}} / d_{\mathrm{ni}}>10$. It is known that the cavity depth $h_{\mathrm{j}}$

\footnotetext{
* Corresponding author: E-mail: shing-sato@jfe-steel.co.jp DOI: https://doi.org/10.2355/isijinternational.ISIJINT-2019-790
}

at a high lance position can be arranged by the momentum number $\mathrm{M}_{\mathrm{m}} \cdot{ }^{10)}$ In this far field range, the velocity on the central axis of the jet decreases almost in inverse proportion to the distance $x$ from the lance exit, while the jet width increases in proportion to the distance. However, the conventional empirical expression proposed as a function of the momentum number cannot be applied in the vicinity of lance. This study attempts to clarify the phenomena of cavity formation, fluctuation of the bath surface and droplet generation by model experiments and numerical simulation when $h_{\mathrm{n}} / d_{\mathrm{ni}}$ is smaller than 10 (near field), which is a region with comparatively small energy loss.

The flow phenomena in the converter are often evaluated by water model experiments because molten steel and water have almost the same kinematic viscosity. ${ }^{1-5)}$ According to a conventional cold model experiment ${ }^{6)}$ using alcohol, a glycerin aqueous solution and carbon tetrachloride instead of water, the surface tension and viscosity of the liquid have little effect on cavity formation, which is a source of spitting and splashing. ${ }^{7}$ However, in these cold model experiments, the viscosity of the liquid can be changed drastically, but surface tension can be reduced only slightly, to about $30 \%$ less than that of water $(72 \mathrm{mN} / \mathrm{m})$. Therefore, the results of cold model experiments are not necessarily applicable to study of the effect of surface tension on cavity formation in the converter, because the surface tension of molten steel and water differs by about 20 times. The size and shape of molten steel droplets, which are affected by surface tension, are also likely to be different from those obtained in water model experiments. Although many investigations on spitting and splashing have been carried out in the past, ${ }^{5,8-12)}$ 
only reports for molten steel when $h_{\mathrm{n}} / d_{\mathrm{ni}}$ was sufficiently larger than 10 could be found. ${ }^{13-16)}$ Moreover, while there are many studies using numerical simulation for water, ${ }^{17-19)}$ there are still few numerical studies concerning molten metal. ${ }^{20,21)}$

In this study, model experiments and numerical simulations using Wood's metal and water were carried out to clarify the effect of liquid properties on free surface behavior when a gas jet is blown from a top lance installed near the bath surface in order to investigate the cavity depth of the liquid surface under the near field blowing condition.

\section{Cold Model Experiment Apparatus and Method}

\subsection{Cold Model Experiments Using Low-Melting- Point Metals}

Figure 1 shows a schematic of the experimental apparatus. A low-melting-point metal, Wood's metal (melting point $\left.73^{\circ} \mathrm{C}\right),{ }^{22)}$ was filled to the predefined bath depth $\left(H_{\mathrm{L}}=\right.$ $100 \mathrm{~mm}$ ) in a cylindrical vessel (diameter $D=200 \mathrm{~mm}$ ) that was sufficiently large in comparison with the inside diameter $\left(d_{\mathrm{ni}}=10 \mathrm{~mm}\right)$ of the top blowing lance. The metal was heated from the bottom of the vessel by the heater, and the metal temperature was adjusted to be approximately constant during the experiment (bath temperature $105^{\circ} \mathrm{C}$ ). Since the experiment was carried out under the atmospheric environment, oxide film (scum) formed on the bath surface, but this scum was removed before each experiment. The top lance was installed at $h_{\mathrm{n}}=8 \mathrm{~mm}$ or $17 \mathrm{~mm}\left(h_{\mathrm{n}} / d_{\mathrm{ni}}=0.8\right.$, $1.7)$ above the liquid surface. The air flow rate $Q_{\mathrm{g}}$ was varied from 44.6 to $129 \mathrm{~L} / \mathrm{min}$, and the air was blown vertically

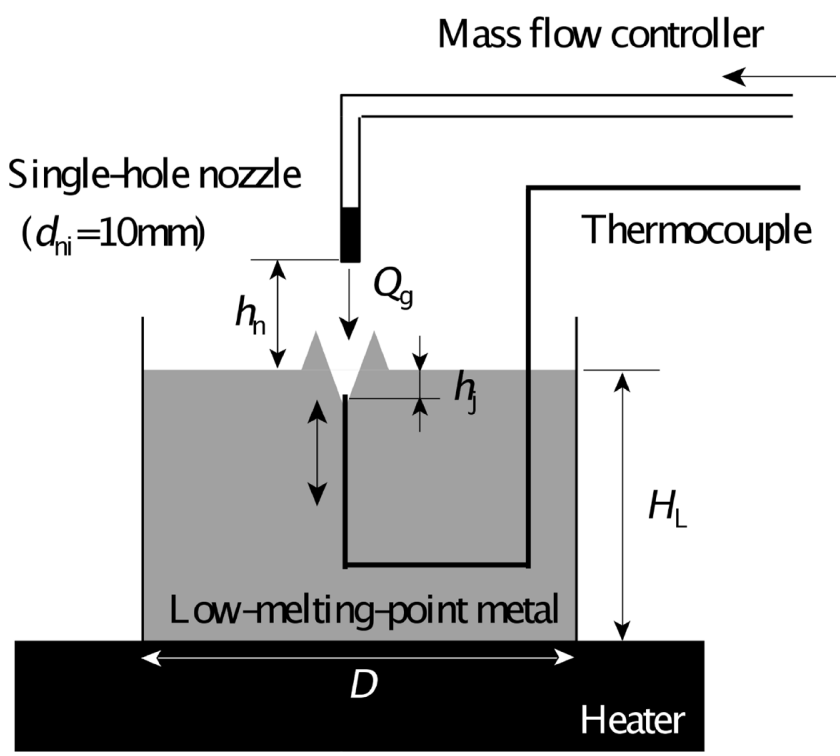

Fig. 1. Schematic of experimental apparatus. toward the liquid surface. The gas jet discharge velocity at the lance outlet is $v_{\mathrm{n}}=9.46$ to $27.4 \mathrm{~m} / \mathrm{s}$ when the air density is constant. The temperature of the air is $27^{\circ} \mathrm{C}(=300 \mathrm{~K})$.

The maximum cavity depth, i.e., the penetration depth $h_{\mathrm{j}}$, formed on the bath surface by gas jet impingement was measured. Since the low-melting-point metal was opaque, the penetration depth was measured by immersing a thermocouple in the metal. The details of the measurement method were as follows: First, the tip of the thermocouple was set higher than the bath surface. After gas blowing, the tip of the thermocouple was gradually lowered, and the thermocouple showed a temperature of $105^{\circ} \mathrm{C}$ when the tip penetrated into the low-melting-point metal. The distance between the thermocouple position at this time and the initial position of the bath surface before gas injection was defined as the penetration depth $h_{\mathrm{j}}$. Since the bath surface during gas blowing fluctuates with time, the measurement was carried out 10 times for each experimental condition in order to reduce the effect of the time fluctuation, and the average value was used. The dispersion of the measured values under each condition was about $\pm 20 \%$ of the average value.

\subsection{Cold Model Experiment Using Water}

The same apparatus as with the low-melting-point metal was also used for the cold model experiment, as shown in Fig. 1. The inner diameter of the top lance $d_{\text {ni }}$, inner diameter of cylindrical vessel $D$ and bath depth $H_{\mathrm{L}}$ were 10,200 and $100 \mathrm{~mm}$, respectively. The lance height $h_{\mathrm{n}}$ was set at 8 or $17 \mathrm{~mm}$, and the air flow rate $Q_{\mathrm{g}}$ was set in the range from 17.6 to $129 \mathrm{~L} / \mathrm{min}$, as in the case of the low-melting-point metal. The penetration depth $h_{\mathrm{j}}$ was measured from the side of the bath using a still camera. Measurements were carried out 10 times for each experimental condition, and the average value was used.

The physical properties of the three fluids used in this study are summarized in Table 1. The surface tension of water and Wood's metal differ by about 6 times.

\section{Numerical Analysis Method}

Computational modeling was carried out using the commercial software STAR-CCM+ ver. 11.02 based on the finite volume method. The incompressible Navier-Stokes equation for gas and liquid phases and continuity equation were used as the governing equations. The two-phase flow was modeled using the volume of fluid (VOF) technique. ${ }^{32}$ ) The turbulent flow was modeled using the realizable $\mathrm{k}-\varepsilon$ model. $^{33)}$ The first-order accuracy implicit method was adopted for the time progress, and the second-order accuracy upwind method was adopted for the convection term. The low-melting-point metal bath and air temperature were

Table 1. Physical properties of fluids.

\begin{tabular}{ccccc}
\hline Fluid & Temperature $\left[{ }^{\circ} \mathrm{C}\right]$ & Density $\left[\mathrm{kg} / \mathrm{m}^{3}\right]$ & Kinematic viscosity $\left[\mathrm{m}^{2} / \mathrm{s}\right]$ & Surface tension $[\mathrm{mN} / \mathrm{m}]$ \\
\hline Water & 27 & 997 & $0.854 \times 10^{-6}$ & 72 \\
Wood's metal $^{22)}$ & 105 & 9560 & $0.341 \times 10^{-6}$ & 431 \\
Air & 27 & 1.17 & $15.29 \times 10^{-6}$ & - \\
\hline
\end{tabular}


$105^{\circ} \mathrm{C}(=378 \mathrm{~K})$ and $27^{\circ} \mathrm{C}(=300 \mathrm{~K})$, respectively. The wall surface of the container was kept in an adiabatic condition.

The numerical simulation was carried out using the same shape as the model experimental equipment. A non-uniform rectangular grid was used, as shown in Fig. 2. The total number of the grid was about 1 million. Strong grid clustering was used in the vicinity of the lance exit and the free surface to capture the gas and liquid flows and deformation of the gas-liquid interface. The lance height $h_{\mathrm{n}}$ was set at 8 or $17 \mathrm{~mm}$, as in the experiment, while the air flow rate $Q_{\mathrm{g}}$ was set in the range from 45 to $250 \mathrm{~L} / \mathrm{min}$. This covers a rather wide flow range, including the experimental conditions. The penetration depth $h_{\mathrm{j}}$ in the numerical analysis was defined as the time average value of the penetration depth after a predetermined period of time by extracting an iso-surface where the volume fraction of the liquid phase was 0.5 on the central axis of the vessel. In this study, the penetration depth was defined as the length after the formation of the first cavity.

A "two-step simulation method" was proposed to solve the supersonic jet and the liquid surface behavior efficiently. ${ }^{19)}$ In this study, a time step $\Delta t$ satisfying the CFL condition can be set large because the velocity of the top blowing lance jet is small. Therefore, the jet behavior of the top lance and the dynamic behavior of the liquid surface were simulated simultaneously.
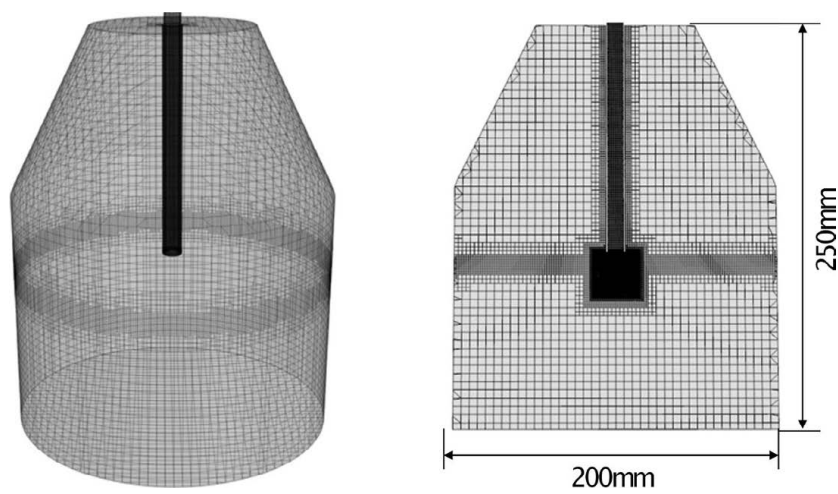

\section{Experimental Results and Numerical Analysis Results}

\subsection{Previous Research on Effect of Gas Flow Rate on Penetration Depth}

In the past, several studies were conducted to clarify the variations of the cavity formed by gas blowing and the spitting phenomena. ${ }^{23-25)}$ Tokuda reported the changes in cavity formation and the spitting phenomenon based on water model experiments. ${ }^{23)}$ Figure 3 shows the relationship between cavity formation and the gas flow rate (with partial amendment). As the air flow rate $Q_{\mathrm{g}}$ increases with a constant lance inside diameter $d_{\text {ni }}$ and lance height $h_{\mathrm{n}}$, the cavity gradually becomes deep (Stage A), and then the liquid around the cavity rises (Stage B). This rise is caused by the shear force along the liquid surface generated by the air flow. With a small additional increase in $Q_{\mathrm{g}}$, the cavity changes to a bubble-like shape, after which a gas column is formed (Stage C). In this stage, the swelling liquid surrounding the cavity is disrupted by strong shear forces, and as a result, many droplets are splashed into the atmosphere. When $Q_{\mathrm{g}}$, is increased further, the gas jet penetrates the liquid, and the tip of the column becomes a bubble, which is entrained in the liquid (Stage D). The phenomena in the stage $\mathrm{D}$ are observed in the case of a high-speed jet with a large Mach number, $\mathrm{M}\left(=v_{\mathrm{n}}{ }^{\prime} / c\right)$, where $v_{\mathrm{n}}$ ' is the velocity of the jet at the bath surface and $c$ is the velocity of sound. In this study, as the first step, we focused on the behavior in stages $\mathrm{A}$ to $\mathrm{C}$ obtained as a result of the experiment and numerical simulation, and compared those results with the previous research by Tokuda. In addition, we attempted to construct an empirical equation for prediction of the penetration depth $h_{\mathrm{j}}$ in each stage, and also examined the gas flow rate as the boundary condition between the stages.

Incidentally, the swirling motion of the cavity caused by the top blowing jet was not mentioned in Fig. 3. The swirling motion occurred under certain conditions in stage $\mathrm{C}^{25)}$ and the cavity also fluctuated in the radial direction. However, the effect of those phenomena on the penetration depth is small.

Fig. 2. Schematic of simulation model.

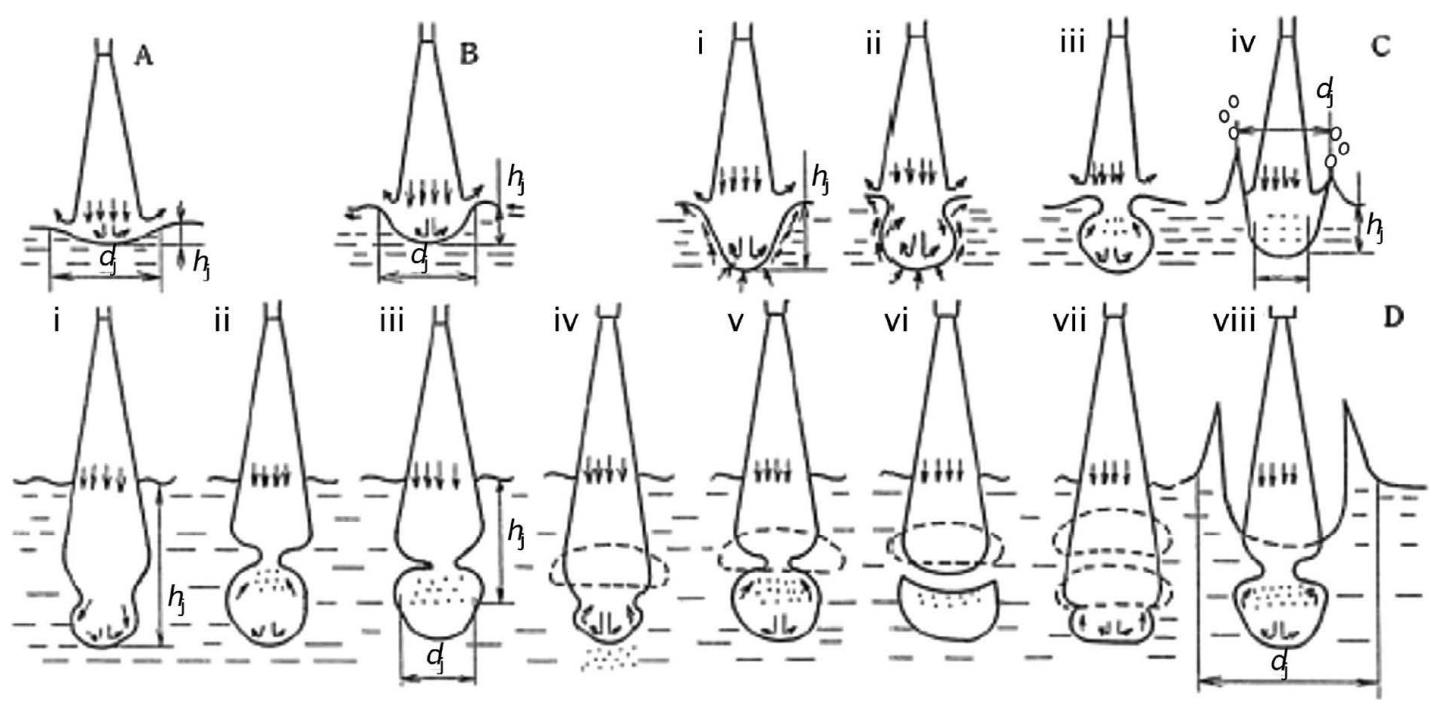

Fig. 3. Relationship between cavity formation and gas flow rate. ${ }^{23)}$ 


\subsection{Experimental Results}

Figures $\mathbf{4}$ and $\mathbf{5}$ show the penetration depth $h_{\mathrm{j}}$ with water and the low-melting-point metal. In the case of water, $h_{\mathrm{j}}$ increases as $Q_{\mathrm{g}}$ increases. This is because the inertial force of the jet impinging on the bath surface increases as the gas flow rate increases. Virtually no effect of the lance position $h_{\mathrm{n}}$ was observed, because the jet velocity at the bath surface $v_{\mathrm{n}}$ ' was almost the same under the present conditions. Kumagai and Iguchi reported that the relationship between the jet velocity at the lance exit $v_{\mathrm{n}}$ and the jet velocity at the bath surface $v_{\mathrm{n}}$ ' shows the following relationship. ${ }^{25)}$

$v_{\mathrm{n}}^{\prime}=v_{\mathrm{n}} \quad\left(h_{\mathrm{n}} / d_{\mathrm{ni}}<1.26\right)$

$$
=\frac{v_{\mathrm{n}}}{0.00523\left(h_{\mathrm{n}} / d_{\mathrm{ni}}-1.26\right)^{2}+1} \quad\left(1.26 \leq h_{\mathrm{n}} / d_{\mathrm{ni}}<17.2\right)
$$

$$
=\frac{v_{\mathrm{n}}}{0.167\left(h_{\mathrm{n}} / d_{\mathrm{ni}}\right)-0.543} \quad\left(17.2 \leq h_{\mathrm{n}} / d_{\mathrm{ni}}\right)
$$

$$
v_{\mathrm{n}}=\frac{4 Q_{\mathrm{g}}}{\pi d_{\mathrm{ni}}^{2}}
$$

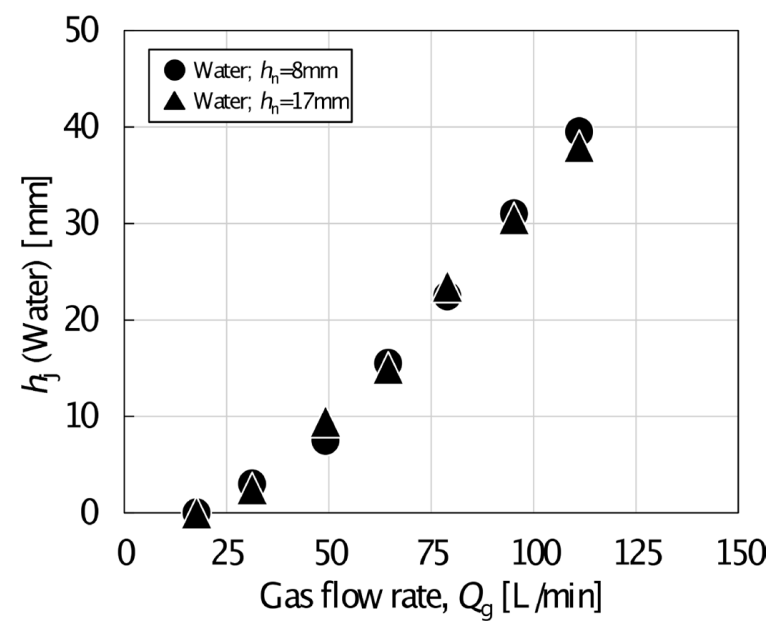

Fig. 4. Measured cavity depth of water.

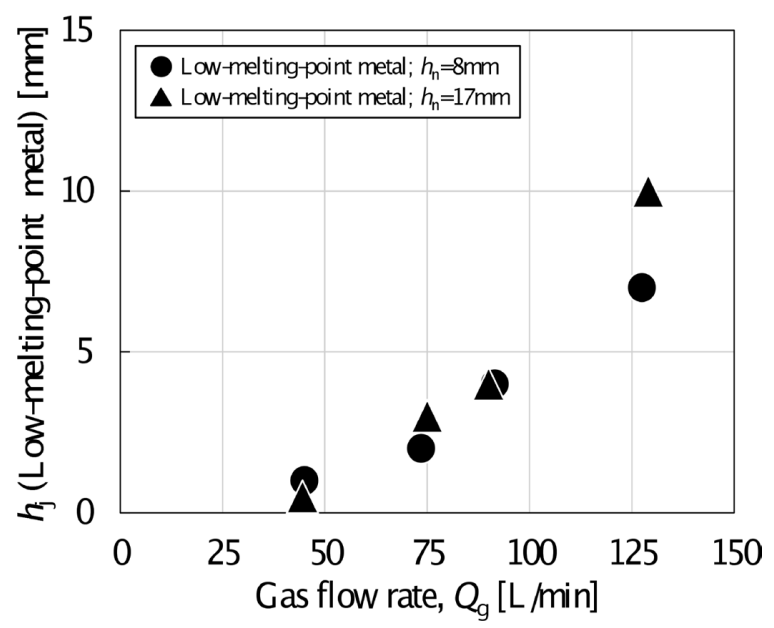

Fig. 5. Measured cavity depth of low-melting-point metal.
Here, $h_{\mathrm{n}}$ is the distance from the bath surface to the lance, $Q_{\mathrm{g}}$ is the gas flow rate and $d_{\mathrm{ni}}$ is the lance inner diameter. When the lance position is in the region $h_{\mathrm{n}} / d_{\mathrm{ni}}<1.26$, the bath surface is in the potential core of the gas jet. Because $h_{\mathrm{n}} / d_{\mathrm{ni}}=0.8$ or 1.7 in this study, $v_{\mathrm{n}}$ was almost the same as $v_{\mathrm{n}}$ ' according to Eq. (1).

As shown in Fig. 5, the penetration depth $h_{\mathrm{j}}$ varied with the lance position $h_{\mathrm{n}}$ under the condition of the gas flow rate $Q_{\mathrm{g}}=125 \mathrm{~L} / \mathrm{min}$. In other words, $h_{\mathrm{j}}$ is larger at $h_{\mathrm{n}}=17 \mathrm{~mm}$ than at $h_{\mathrm{n}}=8 \mathrm{~mm}$, even though the jet velocity at the bath surface $v_{\mathrm{n}}$ ' is almost the same. This is attributed to the accuracy of the measurement method using the thermocouple. When the gas flow rate is increased, bath surface fluctuation increases, and the penetration depth $h_{\mathrm{j}}$ also increases, but because the thermocouple measures the instantaneous value of that fluctuation, it is difficult to measure the penetration depth by using the thermocouple, especially under the large flow rate condition. The difference in $h_{\mathrm{j}}$ is thought to have occurred for this reason.

On the other hand, although $h_{\mathrm{j}}$ increases in proportion to the square of the gas flow rate $Q_{\mathrm{g}}, h_{\mathrm{j}}$ of the low-meltingpoint metal was much smaller than that of the water. This is because the low-melting-point metal, which is a high density substance, produced large buoyancy, thereby suppressing cavity formation.

\subsection{Numerical Simulation Results}

Figure 6 shows the time histories of the penetration depth $h_{\mathrm{j}}$ in a water bath and a low-melting-point metal bath. With both fluids, the penetration depth was deepest immediately after air blowing and then decreased with time after blowing, and as a result, $h_{\mathrm{j}}$ subsided in a state of steady vibration. The time average value of the penetration depth of the simulation results in the steady vibration state was compared with that of the experimental results.

Figure 7 shows the experimental and numerical results of $h_{\mathrm{j}}$ in the low-melting-point metal bath. The numerical results for $h_{\mathrm{j}}$ are in relatively good agreement with the experimental results. Although not shown in this paper, relatively good agreement between the numerical and experimental results for $h_{\mathrm{j}}$ was also obtained with the water bath.

Figure 8 shows the cross-sectional view of the gas-liquid

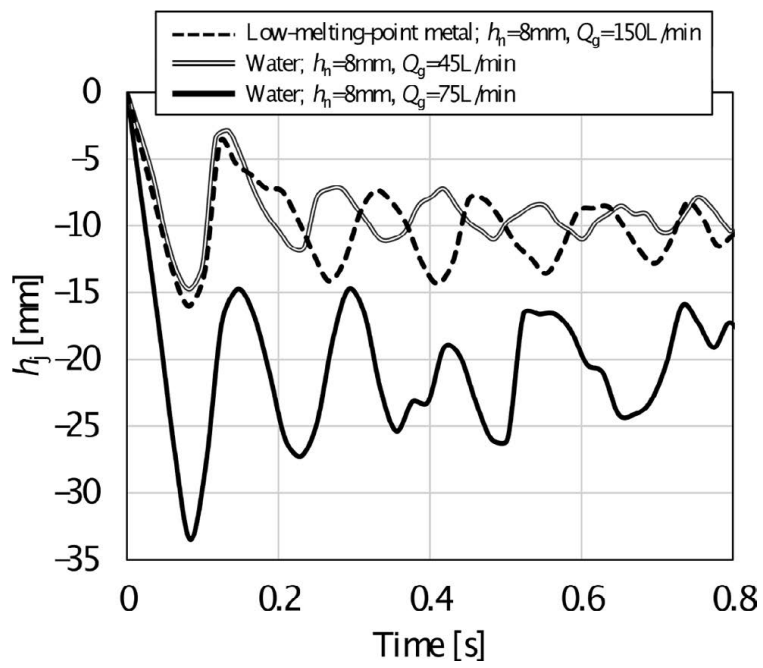

Fig. 6. Time history of cavity depth by simulation. 
interface at $Q_{\mathrm{g}}=90 \mathrm{~L} / \mathrm{min}$ and $250 \mathrm{~L} / \mathrm{min}$ in the numerical simulation. In the case of $90 \mathrm{~L} / \mathrm{min}$, the bath surface was slightly depressed, as in stage A according to Tokuda. ${ }^{23)}$ However, at $250 \mathrm{~L} / \mathrm{min}$, gas column formation and droplet scattering occurred repeatedly, as in Tokuda's stage C. Thus, it was possible to reproduce the behavior of the bath surface described by Tokuda by numerical simulation.

\section{Discussion}

\subsection{Derivation of Empirical Equation for Penetration Depth $\boldsymbol{h}_{\mathrm{j}}$}

Many studies have been conducted on stages C and D, which are related to droplet generation. ${ }^{5,8-12,23)}$ However, fewer studies have investigated stages $\mathrm{A}$ and $\mathrm{B}$. In this study, we focused on stages $\mathrm{A}$ to $\mathrm{C}$ and constructed an empirical equation of the penetration depth $h_{\mathrm{j}}$ in stage A. We also examined an empirical equation for $h_{\mathrm{j}}$ when $h_{\mathrm{n}} / d_{\mathrm{ni}}$ is small (near field) in stage C.

\subsubsection{Stage A}

As shown in Fig. 3, the cavity formed by gas blowing is shaped like part of a sphere. This cavity is the result of the inertial force of the gas jet acting in the downward direction and the buoyancy and surface tension due to static pressure acting in the upward direction. The equation of the force balance is approximately expressed as the following Eq. (3).

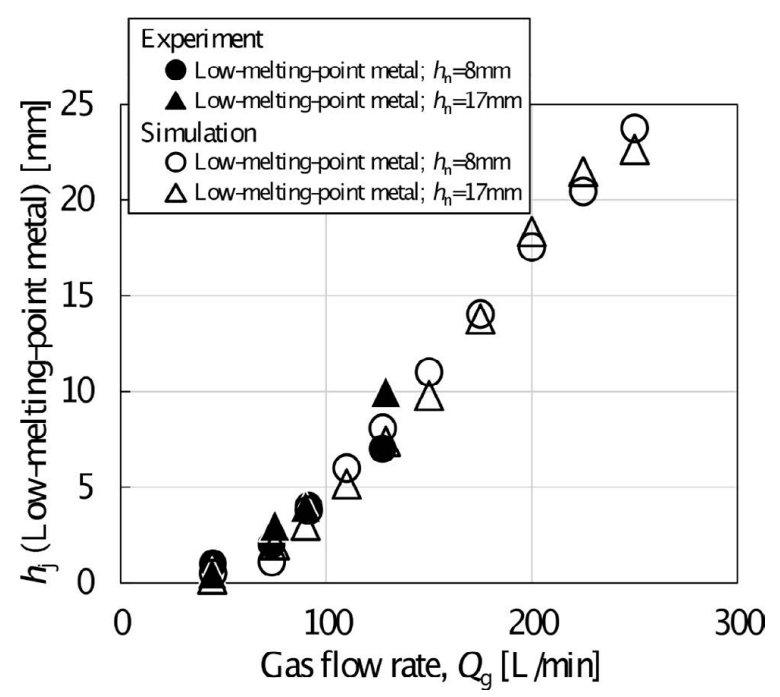

Fig. 7. Cavity depth by experiment and simulation.
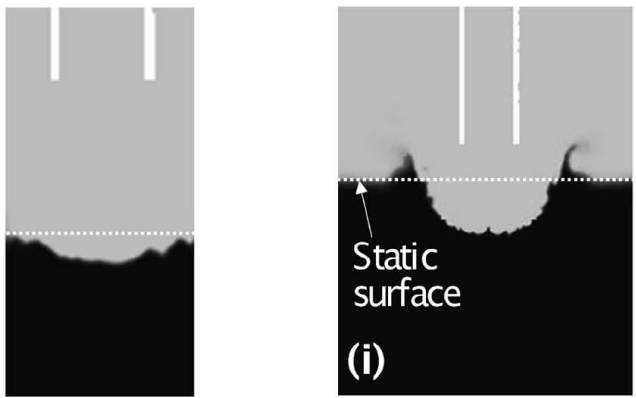

(a) $90 \mathrm{~L} / \mathrm{min}$

$$
\frac{\pi d_{\mathrm{j}}^{2}}{4} \frac{\rho_{\mathrm{g}} v_{\mathrm{n}}^{\prime 2}}{2}=k \frac{\pi d_{\mathrm{j}}^{2}}{4} \rho_{\mathrm{L}} g h_{\mathrm{j}}+\pi d_{\mathrm{j}} \sigma \sin \theta
$$

where, $d_{\mathrm{j}}$ is the diameter of the cavity in the bath surface, $h_{\mathrm{j}}$ is the maximum penetration depth of the cavity, $v_{\mathrm{n}}$ ' is the velocity of the jet at the bath surface $[\mathrm{m} / \mathrm{s}], k$ is an adjustment coefficient $[-], g$ is gravitational acceleration $\left[\mathrm{m} / \mathrm{s}^{2}\right]$, $\sigma$ is surface tension $[\mathrm{N} / \mathrm{m}]$ and $\theta$ is the angle formed by the upper edge of the cavity with the horizontal plane [deg.]. The coefficient $k$ is introduced because hydrostatic pressure does not act equally everywhere on the cavity surface; here, $k$ has a value between 0 and 1 . For the jet velocity at the bath surface $v_{\mathrm{n}}$ ', Eq. (1) proposed by Kumagai et al. ${ }^{25)}$ was used.

Assuming that $\theta$ is sufficiently small, surface tension can be ignored in stage A. Therefore, the equation of the force balance can be approximated by Eq. (4).

$$
\frac{\pi d_{\mathrm{j}}^{2}}{4} \frac{\rho_{\mathrm{g}} v_{\mathrm{n}}^{\prime 2}}{2}=k \frac{\pi d_{\mathrm{j}}^{2}}{4} \rho_{\mathrm{L}} g h_{\mathrm{j}}
$$

From Eq. (4), the penetration depth $h_{\mathrm{j}}$ is given by the following equation.

$$
\begin{array}{r}
h_{\mathrm{j}}=\frac{\rho_{\mathrm{g}} v_{\mathrm{n}}^{\prime 2}}{2 k \rho_{\mathrm{L}} g}=d_{\mathrm{ni}} \frac{\rho_{\mathrm{g}} v_{\mathrm{n}}^{\prime 2}}{2 k \rho_{\mathrm{L}} g d_{\mathrm{ni}}}=d_{\mathrm{ni}}\left(\frac{4}{\pi}\right)^{2} \frac{\mathrm{Fr}_{\mathrm{m}}^{\prime}}{2 k}=\frac{0.811}{k} d_{\mathrm{ni}} \mathrm{Fr}_{\mathrm{m}}^{\prime} \\
\mathrm{Fr}_{\mathrm{m}}^{\prime}=\left(\frac{\pi}{4}\right)^{2} \frac{\rho_{\mathrm{g}} v_{\mathrm{n}}^{\prime 2}}{\rho_{\mathrm{L}} g d_{\mathrm{ni}}} \ldots \ldots \ldots \ldots \ldots \ldots \ldots \ldots \ldots \ldots \ldots \ldots \ldots \ldots \ldots \ldots \ldots \ldots \ldots \ldots \ldots \ldots \ldots \ldots \ldots \ldots \ldots \ldots \ldots \ldots \ldots \ldots \ldots \ldots \ldots \ldots
\end{array}
$$

where, $\mathrm{Fr}_{\mathrm{m}}$ ' is a kind of Froude number which shows the ratio of inertial force and buoyancy force and is called the modified Froude number when the jet velocity at the bath surface $v_{\mathrm{n}}$ ' is used as the velocity. Equation (5) can be expressed as a dimensionless equation as follows.

$$
\frac{h_{\mathrm{j}}}{d_{\mathrm{ni}}}=\frac{0.811}{k} \mathrm{Fr}_{\mathrm{m}}^{\prime}
$$

The value of $k$ is determined by comparing the experimental and numerical results.

\subsubsection{Stage B}

Although Eq. (7) seems to be approximately applicable to stage $B$, the cavity shows a complicated shape in this stage, and the effect of surface tension may also appear. Arrangement of the penetration depth in this stage will be carried out after accumulating experimental and numerical analysis results in the future.
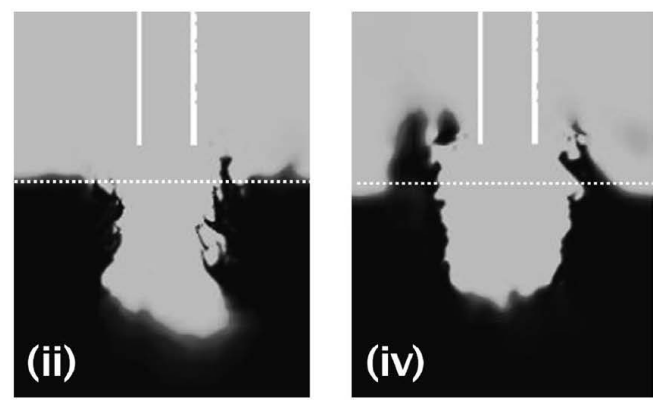

(b) $250 \mathrm{~L} / \mathrm{min}$

Fig. 8. Wave motion on low-melting-point metal bath. 


\subsubsection{Stage C}

According to Tokuda, ${ }^{23)}$ the four processes (i)-(iv) are repeated in stage $\mathrm{C}$. In process (i), the cavity becomes deeper than in stage B, and in processes (ii) and (iii), the tip of the air column takes a bubble-like shape. If the inlet of the air column is constricted in process (iii), the jet rebounds upward without contributing to the formation of the cavity. Then, in process (iv), the bubble in the bath floats to the bath surface, and droplets are generated. Many empirical equations for stage $\mathrm{C}$ have been reported for the case of large $h_{\mathrm{n}} / d_{\mathrm{ni}}{ }^{1-6,13-16)}$ Some of the equations proposed for water and molten metal are shown below. The modified Froude number $\mathrm{Fr}_{\mathrm{m}}$ defined by the following Eq. (8) is frequently used for the cavity formation behavior by gas blowing.

$$
\mathrm{Fr}_{\mathrm{m}}=\left(\frac{\pi}{4}\right)^{2} \frac{\rho_{\mathrm{g}} v_{\mathrm{n}}^{2}}{\rho_{\mathrm{L}} g d_{\mathrm{ni}}}
$$

$\mathrm{Fr}_{\mathrm{m}}$ ' defined by Eq. (6) is the value $v_{\mathrm{n}}$ ' is used, whereas $\mathrm{Fr}_{\mathrm{m}}$ defined by Eq. (8) is the value when $v_{\mathrm{n}}$ is used. When rearranging the behavior of cavity formation at the bath surface, it would be desirable to use $\mathrm{Fr}_{\mathrm{m}}$. However, $\mathrm{Fr}_{\mathrm{m}}$ ' is used because it is difficult to calculate the jet velocity at the bath surface, as shown by the following past studies.

(1) Empirical equation by Tanaka et al.

Tanaka et al. proposed the following Eq. (9) for a waterair system. ${ }^{10)}$

$$
\frac{h_{\mathrm{j}}}{h_{\mathrm{n}}}\left(1+\frac{h_{\mathrm{j}}}{h_{\mathrm{n}}}\right)^{2}=\frac{15.2^{2}}{2 \pi} \frac{\dot{p}}{\rho_{\mathrm{L}} g h_{\mathrm{n}}^{3}}=\frac{15.2^{2}}{2 \pi} \mathrm{M}_{\mathrm{m}}
$$

where, $p$ is the momentum of the gas at the lance exit and $\mathrm{M}_{\mathrm{m}}$ is the momentum number [-] given by the following equations, respectively.

$$
\begin{array}{r}
\dot{p}=\dot{m}_{\mathrm{g}} v_{\mathrm{n}}=\rho_{\mathrm{g}} Q_{\mathrm{g}} v_{\mathrm{n}}=\rho_{\mathrm{g}} \frac{\pi d_{\mathrm{ni}}^{2}}{4} v_{\mathrm{n}}^{2} \ldots \ldots \ldots \ldots . . . . . .(10) \\
\mathrm{M}_{\mathrm{m}}=\frac{\dot{p}}{\rho_{\mathrm{L}} g h_{\mathrm{n}}^{3}}=\frac{\pi}{4} \frac{\rho_{\mathrm{g}} d_{\mathrm{ni}}^{2} v_{\mathrm{n}}^{2}}{\rho_{\mathrm{L}} g h_{\mathrm{n}}^{3}}=\frac{\pi}{4}\left(\frac{d_{\mathrm{ni}}}{h_{\mathrm{n}}}\right)^{3} \frac{\rho_{\mathrm{g}} v_{\mathrm{n}}^{2}}{\rho_{\mathrm{L}} g d_{\mathrm{ni}}}=\frac{4}{\pi}\left(\frac{d_{\mathrm{ni}}}{h_{\mathrm{n}}}\right)^{3} \mathrm{Fr}_{\mathrm{m}}
\end{array}
$$

Using Eqs. (10) and (11), Eq. (9) can be transformed as follows.

$$
\frac{h_{\mathrm{j}}}{h_{\mathrm{n}}}\left(1+\frac{h_{\mathrm{j}}}{h_{\mathrm{n}}}\right)^{2}=46.8\left(\frac{d_{\mathrm{ni}}}{h_{\mathrm{n}}}\right)^{3} \mathrm{Fr}_{\mathrm{m}}
$$

The validity range of this equation is $\mathrm{M}_{\mathrm{m}}=0.002$ to 0.25 , but the measured values for the water-air system obtained in the present study were in the range of $\mathrm{M}_{\mathrm{m}}=0.112$ to 9.18. Therefore, the measured values at small $\mathrm{M}_{\mathrm{m}}$ can be compared using Eq. (12).

(2) Empirical equation by Ishikawa et al.

Ishikawa et al. proposed the following Eq. (13) for the penetration depth $h_{\mathrm{j}}$ in a water-nitrogen system. ${ }^{5}$ )

$$
\frac{h_{\mathrm{j}}}{d_{\mathrm{ni}}}=\frac{h_{\mathrm{j} 0}}{d_{\mathrm{ni}}} \exp \left(-1.77 \frac{h_{\mathrm{n}}}{h_{\mathrm{j} 0}}\right)
$$

where, $h_{\mathrm{j} 0}$ is the cavity depth in the case of $h_{\mathrm{n}}=0$. Some parameters in Eq. (13) are converted to symbols in this paper.

$$
\begin{aligned}
\frac{h_{\mathrm{j} 0}}{d_{\mathrm{ni}}}=0.426\left(\frac{Q_{\mathrm{g}}}{d_{\mathrm{ni}}^{2} \sqrt{g d_{\mathrm{ni}}}}\right)^{2 / 3} \\
=0.426\left(\frac{\pi}{4}\right)^{-2 / 3}\left(\frac{\pi^{2} \rho_{\mathrm{L}}}{16 \rho_{\mathrm{g}}}\right)^{1 / 3}\left\{\left(\frac{\pi}{4}\right)^{2} \frac{\rho_{\mathrm{g}} v_{\mathrm{n}}^{2}}{\rho_{\mathrm{L}} g d_{\mathrm{ni}}}\right\}^{1 / 3}=4.04 \mathrm{Fr}_{\mathrm{m}}^{1 / 3} \\
\frac{h_{\mathrm{n}}}{h_{\mathrm{j} 0}}=\frac{h_{\mathrm{n}}}{4.04 d_{\mathrm{ni}} \mathrm{Fr}_{\mathrm{m}}^{1 / 3}} \ldots \ldots \ldots \ldots \ldots \ldots \ldots \ldots \ldots \ldots \ldots \ldots \ldots \ldots \ldots \ldots \ldots \ldots \ldots \ldots \ldots \ldots \ldots \ldots \ldots \ldots \ldots \ldots \ldots \ldots
\end{aligned}
$$

The liquid and gas densities were given the values of water and air. The following Eq. (16) was obtained by using Eqs. (13), (14) and (15).

$$
\frac{h_{\mathrm{j}}}{d_{\mathrm{ni}}}=4.04 \mathrm{Fr}_{\mathrm{m}}^{1 / 3} \exp \left(-0.438 \frac{h_{\mathrm{n}}}{d_{\mathrm{ni}}} \operatorname{Fr}_{\mathrm{m}}^{-1 / 3}\right) \ldots \ldots \ldots
$$

The validity range of this equation is $h_{\mathrm{n}} / h_{\mathrm{j} 0}=0.03$ to 0.65 , $h_{\mathrm{n}} / d_{\mathrm{ni}}=0$ to 100 , whereas the ranges in the present study are $h_{\mathrm{n}} / h_{\mathrm{j} 0}=0.133$ to $0.682, h_{\mathrm{n}} / d_{\mathrm{ni}}=0.8$ to 1.7 . Equation (16) can be compared with the experimental results of a water-air system.

(3) Empirical equation by Kumagai and Iguchi

Kumagai and Iguchi proposed the following empirical equation. $^{25)}$

$$
\frac{h_{\mathrm{j}}}{d_{\mathrm{ni}}}=4.1 \mathrm{Fr}_{\mathrm{m}}^{\prime 1 / 3} \quad\left(2 \leq \mathrm{Fr}_{\mathrm{m}}{ }^{\prime}, h_{\mathrm{n}} / d_{\mathrm{ni}} \leq 20\right)
$$

The range in this study is $\mathrm{Fr}_{\mathrm{m}}{ }^{\prime}=0.07$ to 5.7. Equation (17) can be compared with the experimental results in the range of $\mathrm{Fr}_{\mathrm{m}}{ }^{\prime}>2$.

(4) Empirical equation by Koria and Lange (molten ironoxygen system)

Many studies have been conducted on the penetration depth in a molten iron-oxygen system in case of $h_{\mathrm{n}} / d_{\mathrm{ni}}>$ $10 .{ }^{13-16)}$ Koria and Lange proposed the following equation. ${ }^{16)}$

$$
\begin{aligned}
& \frac{h_{\mathrm{j}}}{h_{\mathrm{n}}}=4.469 \mathrm{M}_{\mathrm{m}}^{0.66} \\
& \mathrm{M}_{\mathrm{m}}=\frac{\dot{p}}{\rho_{\mathrm{L}} g h_{\mathrm{n}}^{3}}=\frac{\pi}{4} d_{\mathrm{ni}}^{2} \frac{1.27\left(p_{0}-p_{\mathrm{a}}\right)}{\rho_{\mathrm{L}} g h_{\mathrm{n}}^{3}}
\end{aligned}
$$

where, $p_{0}$ is the pressure in the oxygen gas supply vessel $[\mathrm{Pa}]$ and $p_{\mathrm{a}}$ is atmospheric pressure $[\mathrm{Pa}]$. Since the exponent of the momentum number $\mathrm{M}_{\mathrm{m}}$ is 0.66 , this equation seems to be applicable to Stage B. Details concerning this point, however, will be discussed in the future, as the experimental and numerical analysis results are currently insufficient, as mentioned above.

In summary, it can be inferred that the penetration depth $h_{\mathrm{j}}$ changes from the 1 st power to the $1 / 3 \mathrm{rd}$ power of the modified Froude number $\mathrm{Fr}_{\mathrm{m}}$ ' as $\mathrm{Fr}_{\mathrm{m}}$ ' increases.

\subsection{Discussion of Lower Boundary of Stage $\mathbf{C}$}

In process (iii) of stage $\mathrm{C}$, the tip of the air column is constricted, forming a bubble-like shape. This suggests that, 
if the critical gas flow rate or critical velocity in which the bubble entrainment phenomenon occurs can be determined, although roughly, it should be possible to predict the lower limit of the range in which Eq. (17) proposed for stage $\mathrm{C}$ holds.

As is well known, quality degradation due to entrainment of mold powder in continuous casting molds has been a problem for many years, and many studies have investigated the mechanism of entrainment responsible for this problem. ${ }^{26-31)}$ Though many entrainment mechanisms have been reported, there is still no established theory. One of the proposed mechanisms is as follows: Molten steel that has entered the mold from the outlet of the immersion nozzle collides with the side wall of the mold and then rebounds back toward the immersion nozzle, and when it comes into contact with the mold powder layer, strong shear stress acts at the interface of the mold powder and the molten steel. When the velocity of the molten steel exceeds a critical value $V_{\text {cr }}$, the mold powder is entrained into the molten steel in the form of droplets. This phenomenon is called mold powder entrainment by steady reverse flow. Asai focused on the work required to pull spherical mold powder drops out of the mold powder layer and proposed the following equation for the critical velocity. ${ }^{31)}$

$$
V_{\mathrm{cr}}=\left\{48 \frac{g\left(\rho_{\mathrm{L}}-\rho_{\mathrm{S}}\right) \sigma_{\mathrm{SL}}}{\rho_{\mathrm{S}}^{2}}\right\}^{1 / 4}
$$

where, $\rho_{\mathrm{S}}$ is the density of the mold powder and $\sigma_{\mathrm{SL}}$ is the interfacial tension.

The phenomenon in which the air blown on the bath surface forms a bubble and is entrained in the liquid is similar to this mold powder entrainment phenomenon. Therefore, $V_{\text {cr }}, \rho_{\mathrm{S}}, \sigma_{\mathrm{SL}}$ are replaced with the symbols $v_{\text {ncr }}, \rho_{\mathrm{g}}, \sigma$ in this paper. $v_{\text {ncr }}$ ' is calculated as follows for the case where the liquid is water or a low-melting-point metal and the gas is air.

(1) Water-air system

$$
\begin{aligned}
V_{\mathrm{ncr}}^{\prime} & =\left\{48 \frac{g\left(\rho_{\mathrm{L}}-\rho_{\mathrm{g}}\right) \sigma}{\rho_{\mathrm{g}}^{2}}\right\}^{1 / 4} \\
& =\left\{48 \frac{9.8(997-1.17) 0.072}{1.17^{2}}\right\}^{1 / 4}=12.6\left[\frac{\mathrm{m}}{\mathrm{s}}\right]
\end{aligned}
$$

(2) Low-melting-point metal-air system

$$
V_{\mathrm{ncr}}^{\prime}=\left\{48 \frac{9.8(9473-1.17) 0.431}{1.17^{2}}\right\}^{1 / 4}=34.4\left[\frac{m}{\mathrm{~s}}\right] \ldots
$$

From these results, it can be understood that the critical velocity of the low-melting-point metal-air system is approximately three times higher than that of the water-air system.

The lance exit velocity under the present experimental conditions is $v_{\mathrm{n}}=9.46$ to $27.4 \mathrm{~m} / \mathrm{s}$. Since $h_{\mathrm{n}} / d_{\mathrm{ni}}$ is 0.8 or 1.7 in the study, it can be determined from Eq. (1) that $v_{\mathrm{n}}$ ' is approximately equal to $v_{\mathrm{n}}$. The critical velocity of the waterair system is $v_{\text {ncr }}{ }^{\prime}=12.6 \mathrm{~m} / \mathrm{s}$, and the measured penetration depth $h_{\mathrm{j}}$ of the water-air system at $v_{\mathrm{n}}{ }^{\prime}>12.6 \mathrm{~m} / \mathrm{s}$ can be approximated by the $1 / 3^{\text {rd }}$ power of $\mathrm{Fr}_{\mathrm{m}}$, , as in Eqs. (12) and (17). On the other hand, the critical velocity of the lowmelting-point metal-air system is $\mathrm{v}_{\mathrm{ncr}}{ }^{\prime}=34.4 \mathrm{~m} / \mathrm{s}$ and can be approximated by Eq. (7) for a gas flow rate $Q_{\mathrm{g}}<162.1$ $\mathrm{L} / \mathrm{min}$ and by the $1 / 3$ rd power of $\mathrm{Fr}_{\mathrm{m}}$ ' at higher values of $Q_{\mathrm{g}}$.

The applicability of Eq. (20) to the object flow field in this study may also be mentioned. According to Asai, when a spherical mold powder droplet passes through the interface between molten steel and mold powder, the mold powder droplet is entrained in the molten steel if the inertial force of the droplet is larger than the sum of the buoyancy acting on the droplet and surface tension, and deduced Eq. (20) for the critical velocity. The same is also true if mold powder is replaced with air and liquid steel is replaced with water or Wood's metal. Therefore, Eq. (20) was applied in the present study. However, in this study, it is difficult to think that a spherical bubble is involved, since a gas is more easily deformed than a liquid, although this depends on the diameter of the bubble. Moreover, if the air flow velocity is large, it is expected to be necessary to consider viscous dissipation. Therefore, Eq. (20) is only an approximate equation, and future examination of the details is necessary.

\subsection{Arrangement by Predictive Equation}

\subsubsection{Water-Air System}

Figures 9 and 10 show the measured and calculated values of the dimensionless cavity depth $h_{\mathrm{j}} / d_{\mathrm{ni}}$, of the water-air system at each lance height for the modified Froude number $\mathrm{Fr}_{\mathrm{m}}$ '. It was converted to SI units in order to derive the empirical equations. The empirical Eqs. (12), (16), and (17) for the water-air system proposed by other researchers are also shown according to their application ranges. Although some of these equations are expressed as a function of $\mathrm{Fr}_{\mathrm{m}}$ and not $\mathrm{Fr}_{\mathrm{m}}$ ', from Eq. (1), it can be concluded that $v_{\mathrm{n}}$ ' is approximately equal to $v_{\mathrm{n}}$ in the range of the present experiment, as the lance position is close to the bath surface $\left(h_{\mathrm{n}} / d_{\mathrm{ni}}=0.8,1.7\right)$. In other words, since $v_{\mathrm{n}}$ is nearly equal to $v_{\mathrm{n}}{ }^{\prime}, \mathrm{Fr}_{\mathrm{m}}{ }^{\prime}=\mathrm{Fr}_{\mathrm{m}}$ can be obtained.

As shown in Figs. 9 and 10, the results of conventional empirical equations for the cavity depth show relatively good agreement when the lance height is large, but tend to deviate greatly when the lance height is small. It is difficult to apply the equations, especially when lance height is small, as they were proposed for the condition of $h_{\mathrm{n}} / d_{\mathrm{ni}}>$

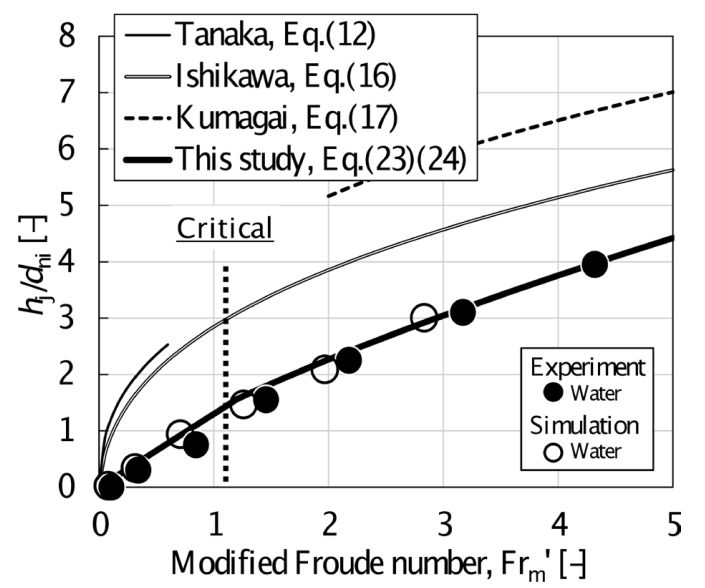

Fig. 9. Dimensionless cavity depth by modified Froude number (water, $h_{\mathrm{n}}=8 \mathrm{~mm}$ ). 


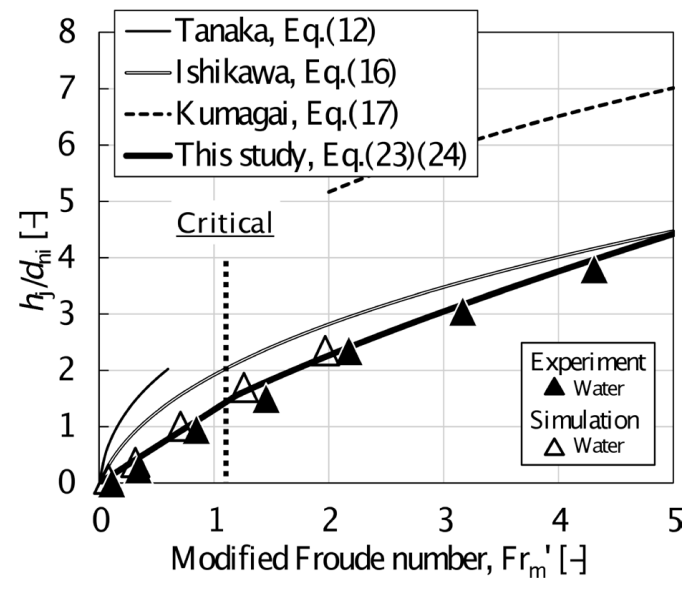

Fig. 10. Dimensionless cavity depth by modified Froude number (water, $h_{\mathrm{n}}=17 \mathrm{~mm}$ ).

10. Therefore, an empirical equation for the cavity depth under the condition of $h_{\mathrm{n}} / d_{\mathrm{ni}}<10$ was examined. Using $12.6 \mathrm{~m} / \mathrm{s}$, the critical value of the modified Froude number is obtained as $\mathrm{Fr}_{\mathrm{mc}}{ }^{\prime}=1.17$ from Eq. (21), which gives the critical velocity for a water-air system. Although this paper includes only a few results (3 levels) below the critical value, the dimensionless cavity depth increases linearly with $\mathrm{Fr}_{\mathrm{m}}$ '. This means that the dimensionless cavity depth is proportional to the square of the jet velocity at the bath surface $v_{\mathrm{n}}$ '. By applying least-square method to the measured and calculated results, the cavity depth in stage A can be expressed by the following Eq. (23).

$$
\frac{h_{\mathrm{j}}}{d_{\mathrm{ni}}}=1.3 \mathrm{Fr}_{\mathrm{m}}{ }^{\prime}
$$

From Eq. (7), the adjustment coefficient $k$ can be determined to be 0.624 . Considering the schematic diagram of stage A in Fig. 3, a value of $k<1$ is valid, but it cannot be determined to be this value due to the limited amount of data.

In the region above the critical value, where $\mathrm{Fr}_{\mathrm{m}}$ ' is in the range of 2 to 6 , there is a slight deviation from the existing empirical equations. By applying least-square method to the measured and calculated results, the following Eq. (24) is proposed as an empirical equation applicable in this range.

$$
\frac{h_{\mathrm{j}}}{d_{\mathrm{ni}}}=1.37 \mathrm{Fr}_{\mathrm{m}}^{0.73}
$$

As shown above, Eq. (21) can be applied approximately to the critical value in the case of water. The critical value can be approximated by the 1st power of $\mathrm{Fr}_{\mathrm{m}}$ ' when the critical value $\mathrm{Fr}_{\mathrm{mc}}$ ' of the modified Froude number is smaller than 1.17 and by the $0.73 \mathrm{rd}$ power of $\mathrm{Fr}_{\mathrm{m}}$ ' when $\mathrm{Fr}_{\mathrm{mc}}$ ' is larger than the critical value. However, as mentioned previously, it cannot be approximated by the $1 / 3$ rd power of $\mathrm{Fr}_{\mathrm{m}}$ ' because the distance from the bath surface to the lance tip was sufficiently smaller than $h_{\mathrm{n}} / d_{\mathrm{ni}}=10$ (i.e., near field range). As it can be approximated by the 0.73 rd power of $\mathrm{Fr}_{\mathrm{m}}$ ' when it is larger than critical value, it can be inferred to approach the $1 / 3$ rd power when $\mathrm{Fr}_{\mathrm{m}}$ ' is larger, but these conditions should be examined in the future.

\subsubsection{Low-Melting-Point Metal-Air System}

Figures 11 and 12 show the measured and calculated

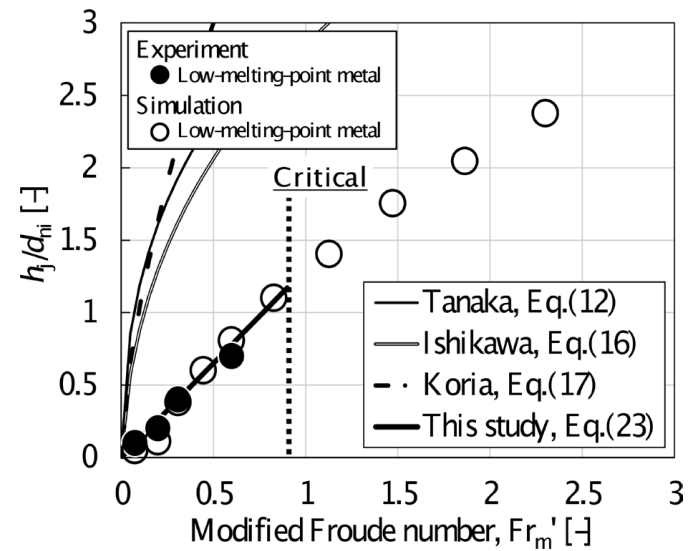

Fig. 11. Dimensionless cavity depth by modified Froude number (low-melting-point metal, $h_{\mathrm{n}}=8 \mathrm{~mm}$ ).

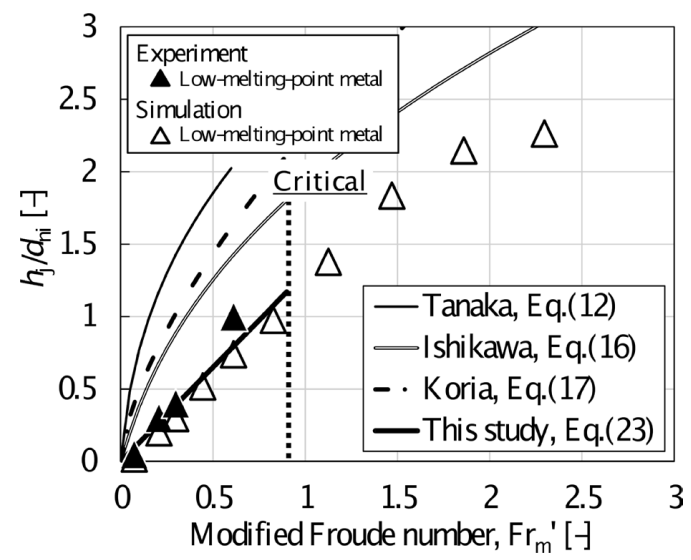

Fig. 12. Dimensionless cavity depth by modified Froude number (low-melting-point metal, $h_{\mathrm{n}}=17 \mathrm{~mm}$ ).

values of $h_{\mathrm{j}} / d_{\mathrm{n}}$, for the low-melting-point metal-air system at each lance height for $\mathrm{Fr}_{\mathrm{m}}$. As in the previous section, the empirical equations proposed by other researchers are also shown according to their application ranges. As can be understood from these figures, the results are significantly different from those by the conventional empirical equations. This shows that application is difficult under the present condition, because those equations were proposed for $h_{\mathrm{n}} / d_{\mathrm{ni}}>10$. Therefore, an empirical equation for the cavity depth in the region of $h_{\mathrm{n}} / d_{\mathrm{ni}}<10$ was examined.

Using $34.4 \mathrm{~m} / \mathrm{s}$, the critical value of the modified Froude number $\mathrm{Fr}_{\mathrm{mc}}=0.911$ from Eq. (22), which gives the critical velocity for the low-melting-point metal-air system. Although all the experimental measurement values are below the critical modified Froude number, they increase linearly with $\mathrm{Fr}_{\mathrm{m}}$ ', and Eq. (7) is applicable. By applying least-square method to the measured and calculated results, the approximated values can be arranged by Eq. (23).

In the numerical analysis, the numerical results for the low-melting-point metal-air system, which are smaller than the critical value of the modified Froude number, approximately agree with the measured values and can be approximated by Eq. (23). On the other hand, when Eq. (24) was applied in the range larger than the critical value, it was found that the agreement between the calculation result and Eq. (24) was comparatively good. However, a strict discussion of the numerical calculation in the region 
where the modified Froude number is $\mathrm{Fr}_{\mathrm{m}}{ }^{\prime}>>0.911$ is not possible, as no measured values are available. This is an issue for the future.

From the results presented above, it is possible to predict the cavity depth by using the same empirical equation, even for the low-melting-point metal-air system in which surface tension differs by about 6 times. That is to say, the effect of surface tension is small in the range of physical property values used in the investigation of the cavity depth in this paper.

\section{Conclusions}

In this report, the effect of liquid properties on the free surface behavior due to the gas jet from a top blowing lance was investigated under near field conditions, that is, when the lance exit is near the bath surface (in this study, $h_{\mathrm{n}} / d_{\mathrm{ni}}=$ $0.8,1.7)$, based on cold model experiments using water and a low-melting-point metal. The results obtained are summarized as follows.

(1) The behavior of the cavity induced near the liquid surface by the gas jet from the top blowing lance was investigated, and a numerical analysis reproduced the behaviors in which stage A appears at a low flow rate and stage $\mathrm{C}$ appears at a high flow rate, as reported by Tokuda.

(2) The following Eqs. (23) and (24) were proposed for the cavity depth in a water-air system.

$$
\begin{gathered}
\frac{h_{\mathrm{j}}}{d_{\mathrm{ni}}}=1.3 \mathrm{Fr}_{\mathrm{m}}{ }^{\prime} \quad\left(0.8 \leq h_{\mathrm{n}} / d_{\mathrm{ni}} \leq 1.7, \mathrm{Fr}_{\mathrm{mc}}{ }^{\prime}<1.17\right) \ldots(23) \\
\frac{h_{\mathrm{j}}}{d_{\mathrm{ni}}}=1.37 \mathrm{Fr}_{\mathrm{m}}^{\prime 0.73} \quad\left(0.8 \leq h_{\mathrm{n}} / d_{\mathrm{ni}} \leq 1.7,1.17 \leq \mathrm{Fr}_{\mathrm{mc}}{ }^{\prime}<5.5\right)
\end{gathered}
$$

(3) It was found that the cavity depth of the low-melting-point metal-air system can be arranged by Eq. (23) for the cavity depth in a water-air system in the region below the critical velocity.

\section{REFERENCES}

1) R. D. Collins and H. Lubanska: Br. J. Appl. Phys., 5 (1954), 22.

2) K. Segawa, S. Maehara, M. Shimada and M. Ishibashi: Tetsu-toHagané, 44 (1958), 1056 (in Japanese).

3) M. Shimada, M. Ishibashi, T. Ariyoshi and H. Morise: Tetsu-toHagané, 52 (1966), 1499 (in Japanese).

4) E. T. Turkdogan: Chem. Eng. Sci., 21 (1966), 1133.

5) H. Ishikawa, S. Mizoguchi and K. Segawa: Tetsu-to-Hagané, 58 (1972), 76 (in Japanese).

6) S. Ito and I. Muchi: Tetsu-to-Hagané, 55 (1969), 1164 (in Japanese).

7) J. Szekely and N. J. Themelis: Rate Phenomena in Process Metallurgy, John Wiley \& Sons Inc., Hoboken, NJ, (1971), 684.

8) A. Masui, W. Wenzel and F. R. Block: Tetsu-to-Hagané, 57 (1971), S404 (in Japanese).

9) M. Mori, I. Kobayashi, T. Nakajima, T. Ogino and G. Yoshida: Tetsu-to-Hagané, 70 (1984), S244 (in Japanese).

10) T. Tanaka and K. Okane: Tetsu-to-Hagané, 74 (1988), 1593 (in Japanese).

11) S. Kitamura and K. Okohira: Tetsu-to-Hagané, 76 (1990), 199 (in Japanese).

12) Y. Nakao, T. Ono, M. Mimura, Y. Takeda, H. Horiuchi and T. Oura: Tetsu-to-Hagané, 68 (1982), S14 (in Japanese).

13) J. Maatsch: Tech. Mitt. Krupp Forsch-Ber., 20 (1962), 1.

14) R. A. Flinn, R. D. Pehlke, D. R. Glass and P. O. Hays: Trans. Metall. Soc. AIME, 239 (1967), 1776.

15) S. C. Koria and K. W. Lange: Arch. Eisenhuttenwes., 55 (1984), 427.

16) S. C. Koria and K. W. Lange: Steel Res., 58 (1987), 421.

17) N. Asahara, K. Naito, I. Kitagawa, M. Matsuo, M. Kumakura and M. Iwasaki: Steel Res. Int., 82 (2011), 587.

18) X. Zhou, M. Ersson, L. Zhong, J. Yu and P. Jönsson: Steel Res. Int., 85 (2014), 273.

19) M. Ando, D. Komagata, K. Takahashi, T. Ishii and K. Ueno: Tetsuto-Hagané, 101 (2015), 82 (in Japanese).

20) H. J. Odenthal, W. H. Emling, J. Kempken and J. Schlüter: Iron Steel Technol., 4 (2007), No. 11, 71.

21) Q. Li, M. Li, S. Kuang and Z. Zou: Metall. Mater. Trans. B, 46 (2015), 1494.

22) M. Iguchi and H. Tokunaga: Metall. Mater. Trans. B, 33 (2002), 695.

23) M. Tokuda: 100th and 101st Nishiyama Memorial Seminar, ISIJ, Tokyo, (1984), 41 (in Japanese).

24) V. B. Okhotckii: Izv. VUZ. Cher. Met., 1 (1984), 45.

25) T. Kumagai and M. Iguchi: ISIJ Int., 41 (2001), Supple., S52.

26) D. Gupta and A. K. Lahiri: Metall. Mater. Trans. B, 25 (1994), 227.

27) M. Iguchi, J. Yoshida, T. Shimizu and Y. Mizuno: ISIJ Int., 40 (2000), 685 .

28) H. Tanaka, H. Kuwatori and R. Nisihara: Tetsu-to-Hagané, 78 (1992), 761 (in Japanese).

29) Z. Wang, K. Mukai, Z. Ma, M. Nishi, H. Tsukamoto and F. Shi: ISIJ Int., 39 (1999), 795.

30) J. Yoshida, M. Iguchi and S. Yokoya: Tetsu-to-Hagané, 87 (2001), 529 (in Japanese)

31) S. Asai: 100th and 101st Nishiyama Memorial Seminar, ISIJ, Tokyo, (1984), 90 (in Japanese).

32) C. W. Hirt and B. D. Nichols: J. Comput. Phys., 39 (1981), 201

33) T. H. Shih, W. W. Liou, A. Shabbir, Z. Yang and J. Zhu: Comput. Fluids, 24 (1995), 227. 